\title{
Intergyre Salt Transport in the Climate Warming Response
}

\author{
SAMUEL J. LEVANG AND RAYMOND W. SCHMITT \\ Woods Hole Oceanographic Institution, Woods Hole, Massachusetts
}

(Manuscript received 22 July 2019, in final form 23 October 2019)

\begin{abstract}
Regional connectivity is important to the global climate salinity response, particularly because salinity anomalies do not have a damping feedback with atmospheric freshwater fluxes and may therefore be advected over long distances by ocean circulation, resulting in nonlocal influences. Climate model intercomparison experiments such as CMIP5 exhibit large uncertainty in some aspects of the salinity response, hypothesized here to be a result of ocean dynamics. We use two types of Lagrangian particle tracking experiments to investigate pathways of exchange for salinity anomalies. The first uses forward trajectories to estimate average transport time scales between water cycle regimes. The second uses reverse trajectories and a freshwater accumulation method to quantitatively identify remote influences in the salinity response. Additionally, we compare velocity fields with both resolved and parameterized eddies to understand the impact of eddy stirring on intergyre exchange. These experiments show that surface anomalies are readily exchanged within the ocean gyres by the mean circulation, but intergyre exchange is slower and largely eddy driven. These dynamics are used to analyze the North Atlantic salinity response to climate warming and water cycle intensification, where the system is broadly forced with fresh surface anomalies in the subpolar gyre and salty surface anomalies in the subtropical gyres. Under these competing forcings, strong intergyre eddy fluxes carry anomalously salty subtropical water into the subpolar gyre which balances out much of the local freshwater input.
\end{abstract}

\section{Introduction}

The ocean salinity response to climate forcing is an important contributor to ocean circulation change, as salinity influences density gradients that drive the thermohaline circulations (see Kuhlbrodt et al. 2007; Buckley and Marshall 2016; Weijer et al. 2019). In greenhouse gas forcing runs from phase 5 of the Coupled Model Intercomparison Project (CMIP5), the atmospheric water cycle demonstrates a coherent response (Levang and Schmitt 2015) consistent with an amplified water cycle (Held and Soden 2006), where generally wet regions become wetter and dry regions become drier. Despite similar freshwater forcing perturbations, there is poor intermodel agreement for the salinity response in certain regions, particularly the subpolar North Atlantic (see Fig. 7).

Given the similarity in the large scale freshwater forcing patterns in CMIP5, we hypothesize here that uncertainty in the salinity response is partly due to differences in ocean circulation dynamics between the

\footnotetext{
Corresponding author: Samuel J. Levang, slevang@whoi.edu
}

models. The importance of ocean salt transport is clearly evident in the response patterns, where in some locations the salinity change is in fact opposite signed to the freshwater flux (FWF) change, which must be carried by ocean currents between regions. The influence of remote forcing on the salinity field may be more pronounced than for temperature, because salinity anomalies do not have a direct damping feedback with atmospheric freshwater fluxes unlike temperature anomalies and heat fluxes, and are therefore more likely to persist along circulation pathways.

An interesting aspect of the surface salinity response seen in CMIP5 is that freshwater flux trends of different sign become relatively well mixed within the subtropical gyres. Specifically, the subtropical latitudes become more net evaporative and the tropical latitudes more net precipitative, but the salinity change across these regions is relatively uniform (see Figs. 1c,d). Between the subtropical gyres (STG) and subpolar gyres (SPG), most models show a strong contrast in the salinity change particularly in the Atlantic (Fig. 1c; Levang and Schmitt 2015). Freshened SPG waters do 

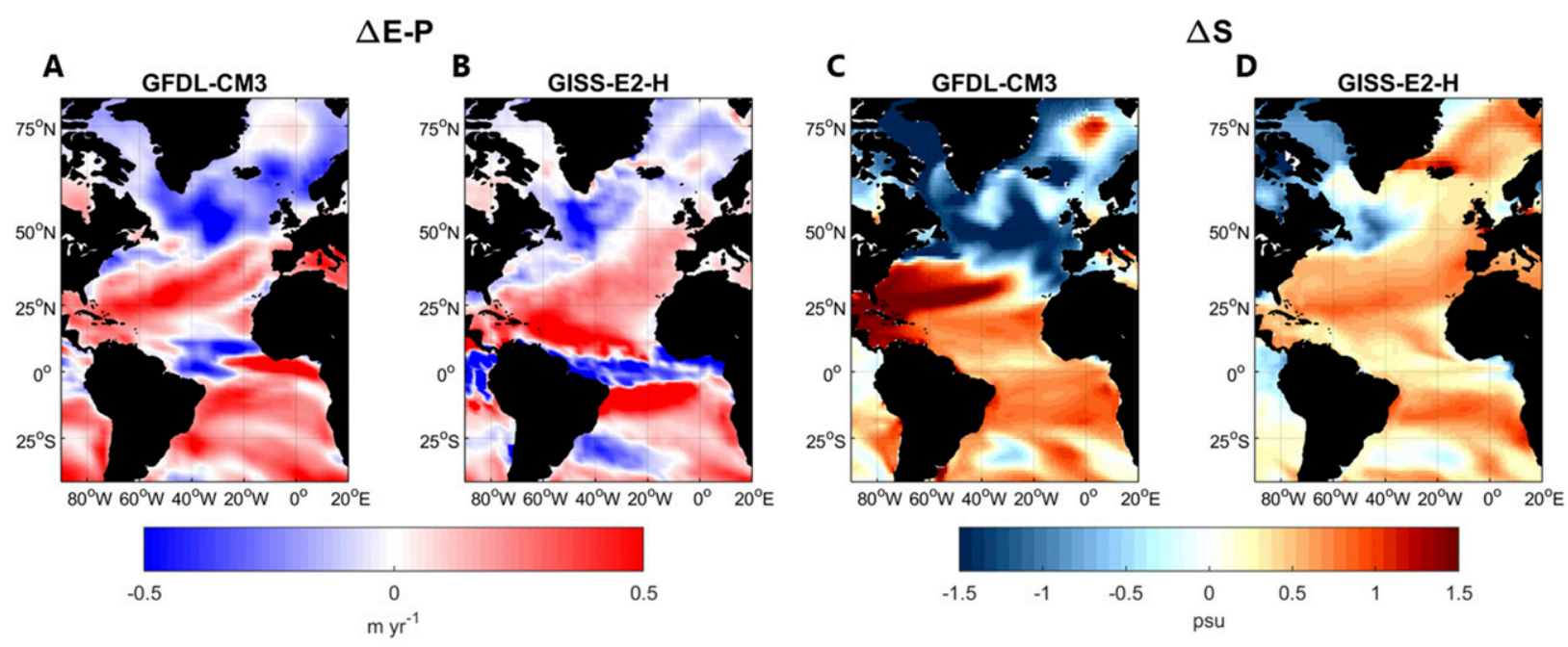

FIG. 1. Comparison of two CMIP5 models, which have similar freshwater forcing trends in the Atlantic but differing surface salinity responses. (a),(c) In GFDL-CM3, subpolar freshening and subtropical salinification remain isolated, while (b),(d) in GISS-E2-H, saltier subtropical water is more dispersed throughout the basin. The trends were calculated by fitting a linear regression to the period 2006-2100 in the RCP8.5 scenario and calculating the total change from the slope.

not appear to mix effectively with saltier STG waters, indicating a transport barrier. In the tropical latitudes, strong surface Ekman flow can disperse anomalous freshwater input in the ITCZ and return salty water from the subtropics via the subsurface return branch of the shallow subtropical cell, effectively mixing these signals. In contrast, the subpolar gyre is isolated from the subtropics by the intergyre boundary.

However, a subset of CMIP5 models show a positive salinity change across much of the subpolar North Atlantic surface, particularly on the eastern side, despite increased local freshwater input (Figs. 1b,d). The only plausible source for salty anomalies in the SPG is subtropical water, pointing to a potential difference in advective intergyre transport between the models. A similar trend of Atlantic SPG salinification is seen in the observational estimate of Durack et al. (2012). These uncertainties motivate a need to better understand the pathway history of surface water masses, and to identify mechanisms and rates of intergyre exchange, particularly in the North Atlantic where salinity is important to the Atlantic meridional overturning circulation (AMOC).

Observational quantification of Lagrangian pathways over decadal and longer time scales is limited. Surface drifters in the Atlantic show very weak exchange between the STG and SPG (Brambilla and Talley 2006), because the true pathways of intergyre exchange are three-dimensional (Burkholder and Lozier 2011; Foukal and Lozier 2016), requiring observations of subsurface flows. Here we explore these pathways using a series of particle tracking experiments in ocean models.

\section{Methods}

While results from CMIP5 serve as motivation, it is not possible to accurately quantify the salt transport in individual CMIP5 models because their standard outputs do not include the eddy-induced residual circulation produced by mixing schemes such as the Gent-McWilliams (GM; Gent and Mcwilliams 1990) and Redi (Redi 1982) parameterizations. Rather than directly analyzing the circulation differences within CMIP5, we consider a simplified version of the problem, which is to take the circulation as a constant using present-day ocean reanalysis products. These velocity fields are used to study how freshwater flux anomalies propagate through the circulation, and to isolate key aspects of the flow that alter the salinity response. This approach provides useful information about the coupled response so long as other climate factors such as winds and temperature do not have $O(1)$ changes on the circulation, and so long as the accumulated salt anomalies do not become large enough to significantly change circulations themselves. These criteria are generally reasonable for present-day centennial climate projections. The AMOC is one potential caveat to the validity of these assumptions, where there is a possibility for large change over the coming century (e.g., Caesar et al. 2018). In the RCP8.5 scenario of CMIP5, a majority of models see a $30 \%-50 \%$ weakening of the AMOC by the year 2100 (Levang and Schmitt 2020). With $O(1)$ 
circulation changes expected, the analysis presented here can be considered analogous to the coupled dynamics until nonlinear advective feedbacks become significant. In the case of a large AMOC weakening, subtropical to subpolar connectivity is lessened and the results here become an upper bound for the influence of subtropical waters on the SPG.

\section{a. Data sources}

For a representation of the present-day ocean circulation, we take velocity fields from two modern dataassimilated ocean models, namely, the Simple Ocean Data Assimilation (SODA) version 3.4.1 (Carton et al. 2018) and Estimating the Circulation and Climate of the Ocean (ECCO) version 4.3 (Forget et al. 2015). These velocity fields are used to produce large ensembles of trajectories used in the experiments here.

ECCO assimilates a wide range of in situ and satellite measurements using the MITgcm over the period 1992-2016. It is run on an Arakawa C-grid in latitudelongitude cap geometry with nominal $1^{\circ}$ horizontal resolution and 50 vertical levels. ECCO uses the GM parameterization for mesoscale eddies, the GasparGrégoris-Lefevre (GGL; Gaspar et al. 1990) mixed layer closure, and the Redi (1982) scheme for isopycnal diffusion. ECCO is similar in resolution and parameterizations to most CMIP5 models. We use the rectilinear $0.5^{\circ}$ interpolated velocity fields for producing trajectories.

SODA also assimilates many in situ and satellite measurements, and the version 3.4.1 used here incorporates atmospheric forcing from the ERA-Interim reanalysis for the period 1981-2015. It is run using the GFDL MOM2.5 ocean model (Delworth et al. 2012), which utilizes a tripolar Arakawa B-grid with $0.25^{\circ}$ horizontal resolution at the equator, increasing to $0.1^{\circ}$ at the poles, and 50 vertical levels. We use the native B-grid output for trajectories south of $65^{\circ} \mathrm{N}$, and interpolate the tripolar fields to a rectangular grid north of this point.

SODA does not utilize any mesoscale eddy parameterization such as GM, but uses the submesoscale closure of Fox-Kemper et al. (2011) and the KPP (Large et al. 1994) vertical mixing scheme. SODA also does not apply any background lateral or vertical diffusion. SODA can be considered eddy-permitting nearly everywhere. The increased resolution at high latitude allows for grid spacing near half the first baroclinic Rossby radius of deformation, which is required to represent classical mesoscale eddies. The underlying MOM2.5 ocean model has realistic patterns of enhanced eddy kinetic energy in the deep tropics, western boundary currents, and frontal zones, but is somewhat less energetic everywhere when compared to altimeter observations or higher resolution configurations of MOM (Delworth et al. 2012). Additionally, we use a monthly climatology of the SODA model as a field with no representation of eddies at all, since transient features are filtered out by taking a temporal mean of the velocity fields.

Trajectories are produced from 5-day averaged SODA velocities. Averaging time scales up to 9 days have been found to produce accurate trajectories within a mesoscale flow (Qin et al. 2014). ECCO trajectories are produced from 30-day averaged velocities, which is sufficient because the coarse-resolution flow contains much less transient variability on submonthly time scales.

We also use output from the RCP8.5 scenario of the CMIP5 ensemble over the period 2006-2100 to obtain a multimodel mean anomalous freshwater flux trend to apply to the trajectories as a passive salinity tracer, taken from the CMIP5 variable water flux into ocean (wfo). For the basin-integrated freshwater forcing tendencies shown in Fig. 4, the CMIP5 variables evaporation (evspbl) minus precipitation (pr) are shown for better visualization of the flux changes over land which force river runoff changes. The land areas have been assigned to each basin according to drainage basins defined by continental topographic maxima, such that the basin-integrated $E-P$ including land areas is nearly equivalent to $E-P-R$ over the oceans. This formulation also avoids errors to do regridding of point-source river mouths. All CMIP5 values are given as a multimodel mean of the models listed in Table 1. For the basinwide forcing tendencies, the error bars are given as the standard deviation between models.

\section{b. Particle advection scheme}

Trajectories are generated with an offline advection model utilizing the Runge-Kutta fourth-order (RK4) time-stepping scheme. The local velocity for each particle is determined through a trilinear interpolation of the three-dimensional velocity fields in space and a linear interpolation between each time step of the model output. Particle positions are calculated at 1-h time steps to satisfy the stability criteria for explicit integration schemes, and stored every 5 days. The particle tracking software used here was built from scratch to obtain fast computation time for the 100-yr trajectories required in this analysis by making use of GPU parallelization. The tracking algorithms were tested against similar software packages such as PARCELS (Lange and van Sebille 2017).

Several processes that are effectively subgrid scale or otherwise parameterized in an Eulerian model must be handled within the offline advection scheme in addition 
TABLE 1. List of CMIP5 models used for the variables of freshwater flux into the ocean (wfo), salinity (so), evaporation (evspsbl), precipitation (pr), and isopycnal diffusion $\left(\kappa_{\text {Redi }}\right)$. Further details for each model may be found in Flato et al. (2014).

\begin{tabular}{|c|c|c|c|}
\hline Institute & Model & CMIP5 variable: wfo & CMIP5 variables: so, evspsbl, pr, $\kappa_{\text {redi }}$ \\
\hline $\mathrm{BCC}$ & BCC_CSM1.1 & $\mathrm{X}$ & \\
\hline BNU & BNU-ESM & $\mathrm{X}$ & $\mathrm{X}$ \\
\hline CCCma & CanESM2 & $\mathrm{X}$ & $\mathrm{X}$ \\
\hline CMCC & CMCC-CM & $\mathrm{X}$ & \\
\hline CNRM-CERFACS & CNRM-CM5 & $\mathrm{X}$ & $\mathrm{X}$ \\
\hline ICHEC & EC-EARTH & $\mathrm{X}$ & \\
\hline INM & INM-CM4 & $\mathrm{X}$ & \\
\hline IPSL & IPSL-CM5A-LR & & $\mathrm{X}$ \\
\hline IPSL & IPSL-CM5A-MR & $\mathrm{X}$ & $\mathrm{X}$ \\
\hline IPSL & IPSL-CM5B-LR & & $\mathrm{X}$ \\
\hline CESS & FGOALS-g2 & $\mathrm{X}$ & $\mathrm{X}$ \\
\hline JAMSTEC & MIROC-ESM & $\mathrm{X}$ & $\mathrm{X}$ \\
\hline JAMSTEC & MIROC-ESM-CHEM & $\mathrm{X}$ & $\mathrm{X}$ \\
\hline JAMSTEC & MIROC5 & $\mathrm{X}$ & $\mathrm{X}$ \\
\hline MOHC & HadGEM2-CC & $\mathrm{X}$ & $\mathrm{X}$ \\
\hline MOHC & HadGEM2-ES & $\mathrm{X}$ & $\mathrm{X}$ \\
\hline MPI-M & MPI-ESM-LR & & $\mathrm{X}$ \\
\hline MPI-M & MPI-ESM-MR & $\mathrm{X}$ & $\mathrm{X}$ \\
\hline MRI & MRI-CGCM3 & $\mathrm{X}$ & $\mathrm{X}$ \\
\hline NASA GISS & GISS-E2-H & $\mathrm{X}$ & $\mathrm{X}$ \\
\hline NASA GISS & GISS-E2-H-CC & $\mathrm{X}$ & $\mathrm{X}$ \\
\hline NASA GISS & GISS-E2-R & $\mathrm{X}$ & $\mathrm{X}$ \\
\hline NASA GISS & GISS-E2-R-CC & $\mathrm{X}$ & $\mathrm{X}$ \\
\hline NCAR & CCSM4 & $\mathrm{X}$ & $\mathrm{X}$ \\
\hline NCC & NorESM1-M & $\mathrm{X}$ & $\mathrm{X}$ \\
\hline $\mathrm{NCC}$ & NorESM1-ME & $\mathrm{X}$ & $\mathrm{X}$ \\
\hline NOAA/GFDL & GFDL CM3 & $\mathrm{X}$ & $\mathrm{X}$ \\
\hline NOAA/GFDL & GFDL-ESM2G & $\mathrm{X}$ & $\mathrm{X}$ \\
\hline NOAA/GFDL & GFDL-ESM2M & $\mathrm{X}$ & $\mathrm{X}$ \\
\hline NSF, DOE, NCAR & CESM1(BGC) & $\mathrm{X}$ & $\mathrm{X}$ \\
\hline NSF, DOE, NCAR & CESM1(CAM5) & $\mathrm{X}$ & $\mathrm{X}$ \\
\hline
\end{tabular}

to the standard model velocity outputs in order to obtain realistic particle behavior.

The first of these is vertical motion within the surface mixed layer (SML). In the Eulerian frame, the energetic stirring and vertical transport of tracers within the SML is parameterized by KPP or other closure schemes. To represent this transport in terms of Lagrangian particles, we apply a simple displacement of the particle positions at regular intervals whenever the particle is found to be within the SML defined by a density criterion of $\rho_{z}-\rho_{0}>0.03 \mathrm{~kg} \mathrm{~m}^{-3}$, which generates a random walk for particles within the SML. The interval for displacements is chosen to be once per day, which limits vertical motions even in deep SMLs to $O(0.1) \mathrm{m} \mathrm{s}^{-1}$ that have been observed in convective plumes (Lavender et al. 2002), but allows for frequent motions within the SML on the time scale of resolved mesoscale features. This scheme does not provide any diapycnal transport of particles across the SML base.

Another issue associated with subgrid motions is the treatment of particles within the boundary cells of the model. If particles cross the boundary cells, they become stranded outside the domain. To avoid stranding, we apply a no normal flow boundary condition when a particle reaches the edge of the domain, such that particles will continue to move along the cell boundary if there is a nonzero velocity component in the remaining dimensions.

The ECCO model uses the GM scheme to parameterize the effects of mesoscale eddies as an advective residual-mean velocity. To capture this behavior in trajectories, the additional GM velocity term is simply added to the Eulerian velocities during particle advection, mimicking the transport of tracers in the Eulerian model.

Other subgrid mixing parameterizations, such as the isopycnal Redi (1982) scheme, do not have a direct advective analog that can be applied to trajectories. A common procedure is to apply an additional stochastic velocity to create particle spreading which mimics the tracer diffusion of these terms. We use a first-order Markov model (van Sebille et al. 2018), which applies a random velocity at each time step as $u_{\text {diff }}=\sqrt{\kappa_{\text {Redi }} / \Delta t}$, where $\kappa_{\text {Redi }}$ is a diffusivity and $\Delta t$ is the advective time 
step. We vary the diffusivity to test the effects of isopycnal stirring strength.

To sample the annual and interannual variability of the flow fields used, particles are launched monthly over a period of 5 years. Launch locations are randomly generated within $1^{\circ}$ grid cells. The number of particles used in the global salinity accumulation experiments is $1.5 \times 10^{6}$.

Because the ECCO and SODA outputs used here only extend for 25-35 years, longer trajectories must be looped through the model output multiple times. This is a common technique for particle tracking over long time scales and other authors have found limited impact on bulk results (van Sebille et al. 2018). For 100-yr trajectories, the looping induces 2-3 discontinuities in the velocity fields. These velocity jumps may induce erroneous spreading across the flow regimes of interest. For example, a subtropical particle following a northward Gulf Stream meander may suddenly appear on the poleward side of the subtropical front as the velocity field loops. To test the importance of this effect, we compare the SODA run with 2 discontinuities to one in which the model output years are randomly rearranged, so that the velocity field has a jump every year (100 total). Even for this large number of discontinuities, we find that the subtropical to subpolar exchange time scale decreases by only $10 \%$ and conclude that a small number of loops has a minimal effect on the analysis.

\section{c. Transport time scales}

To understand the exchange of freshwater signals between different hydrologic regimes, we launch an ensemble of $1.0 \times 10^{6}$ particles evenly distributed across the global ocean surface layer at 5-m depth. We analyze exchange by defining broad regions corresponding to the sign of freshwater forcing change under water cycle intensification, and measure the average transit properties of all particles launched in each region. For the subtropical regions, we take the poleward edge to be the intergyre boundary, defined as a surface of constant mean dynamic topography within the model outputs (as in Zou and Lozier 2016), for which streamlines immediately equatorward (poleward) of the contour recirculate in the STG (SPG). We choose this definition rather than the $E-P=0$ contour (which lies slightly equatorward of the intergyre boundary) because many subtropical particles will repeatedly cross the $E-P=0$ line but then recirculate into the STG. The tropical regions which see increased net precipitation do not have an obvious dividing contour based on circulation, so we choose a simple latitude band of $5^{\circ} \mathrm{S}-10^{\circ} \mathrm{N}$ to represent the waters freshened by increased ITCZ rainfall under water cycle intensification.
A cumulative transport function is produced by identifying the first instance when a particle crosses into a region other than its origin and remains there for at least two months. The residence time requirement eliminates false crossings where particles continue to follow geostrophic streamlines that recirculate at the intergyre boundary, but temporarily cross the fixed boundary line due to transient meanders. Once a particle has met this threshold, it does not add to the transport if it crosses the boundary again.

\section{d. Trajectory histories and accumulation of salinity anomalies}

To quantify the influence of regional connections on salinity changes, we calculate an average forcing history for a large ensemble of reverse trajectories. Because a water parcel is directly affected by surface fluxes only when it is within the SML, we define a metric $\alpha_{l, t}$, which produces a map of the relative geographic influence for water parcels from a particular launch location $l$ and for trajectories of length $t$ :

$$
\alpha_{l, t}(x, y)=\left\langle\int_{0}^{t} \frac{H(z)}{h} d t\right\rangle
$$

where $H(z)$ is a Heaviside function which is nonzero only when the particle depth $z$ is within the SML, $h$ is the SML depth, the integral is over all available trajectories, and the brackets indicate that $\alpha_{l, t}$ is normalized so that the global integral sums to one. The influence is inversely proportional to $h$ because a given surface flux has a weaker effect on tracers when distributed through a deeper mixed layer.

To relate FWF anomalies to salinity change, we accumulate the salinity anomaly as a passive tracer along trajectories. In our model, a water parcel is affected by anomalous FWF any time it is within the SML, with the anomaly evenly distributed across the thickness of the layer. Parcels accumulate forcing along the length of their trajectories with no decay, such that the net salinity change for a particle launched at location $l$ and for trajectories of length $t$ can be calculated as

$$
\Delta S_{l, t}=\oint \frac{S_{0} \Delta \mathrm{FWF}(x, y, t) H(z)}{h} d t
$$

where $S_{0}$ is a reference salinity of $35 \mathrm{psu}, \Delta \mathrm{FWF}$ is an expected freshwater flux anomaly for the particle location (positive defined as out of the ocean), $h$ and $H(z)$ are the same as above, and the integral is calculated along individual particle trajectories. This quantity can then be binned over an ensemble of trajectories to estimate a salinity change everywhere that represents the many possible paths of constituent particles.

To compare the Lagrangian passive tracer method to coupled model results from CMIP5, we take $\Delta \mathrm{FWF}$ to 
A
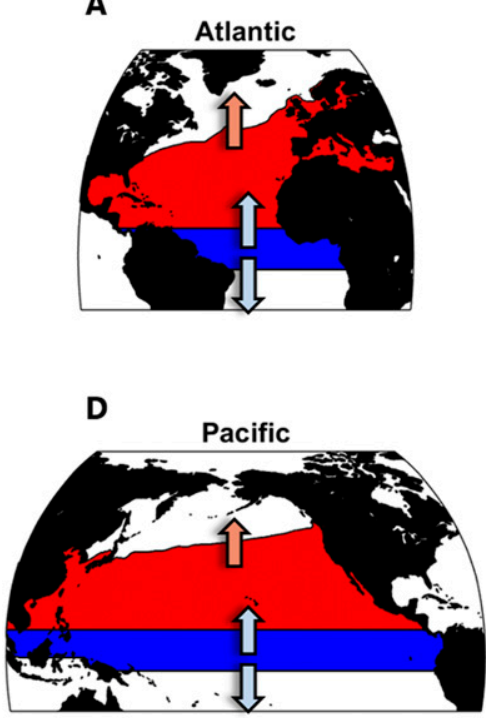

B

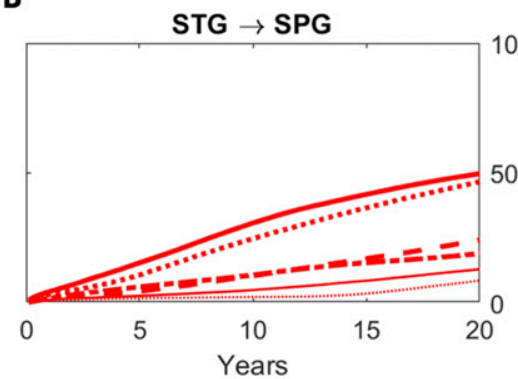

$\mathbf{E}$

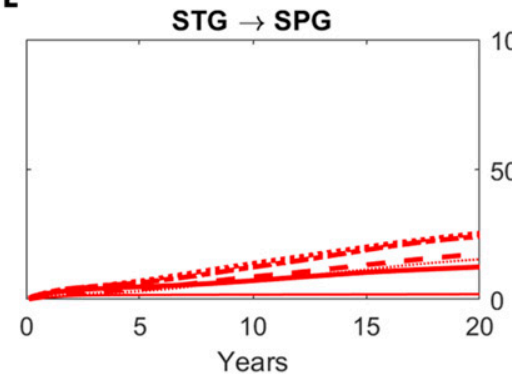

c

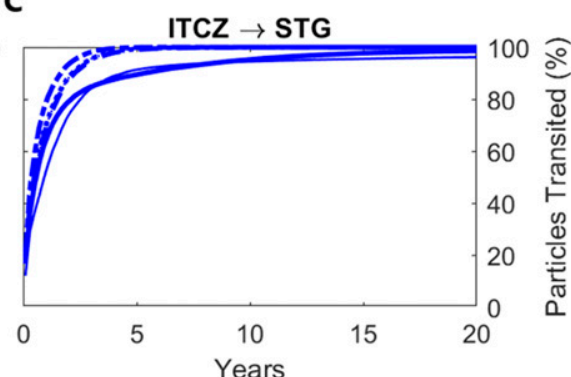

$\mathbf{F}$

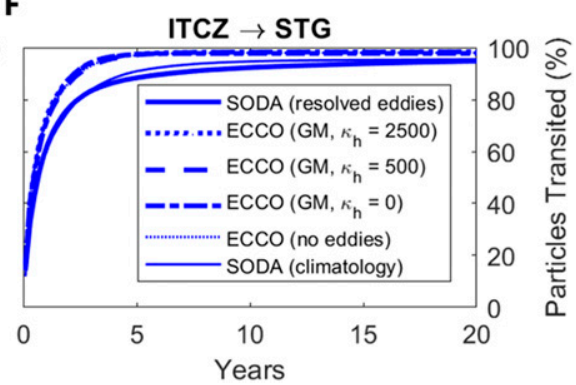

FIG. 2. Particle tracking experiments in the (a) Atlantic and (d) Pacific, where $4 \times 10^{5}$ particles are evenly launched across the subtropical gyre (red) and ITCZ (blue) regions (as defined in the text) and advected forward in time. We calculate the cumulative transit function (as a percent of the total particles launched) for (b),(e) subtropical parcels to spread northward into the subpolar gyre and for (c),(f) ITCZ parcels to spread into either northern or southern subtropical gyres, with trajectories calculated using different eddy representations. The ITCZ spreading time is insensitive to eddy representations, while the STG spreading is highly dependent on eddy stirring.

be the multimodel mean change in the variable wfo from RCP8.5 and apply this field along the trajectories. We produce a monthly trend anomaly map by fitting a linear regression to each of the 12 months for 28 models and averaging the models together. We take the anomaly to be zero in the year 2000 and fit a trend to the period 2006-2100. The actual time-dependent forcing change across the models is well approximated by a linear function. Using this methodology, the salinity anomalies accumulated near the beginning of the 100-yr trajectories (where particles are generally far away from the launch site) are weak, and the anomaly strength increases toward the end of the trajectories (where particles are close to their launch site).

The passive tracer framework makes several assumptions, namely, 1) that salinity anomalies do not generally feedback on circulation or surface fluxes, so that the trajectories may be decoupled from salinity changes, and 2) that particles maintain their accumulated salinity anomalies indefinitely. Previous studies have tested passive tracer methods using a stable circulation in Eulerian models to track temperature change signals, which show good performance, for example, in predicting the propagation of present-day anthropogenic temperature (Marshall et al. 2015), and in attributing ongoing cooling in the deep Pacific to surface heat loss during the Little Ice Age (Gebbie and Huybers
2019). Because salinity does not directly feed back on surface freshwater fluxes, it is likely a better passive tracer than temperature, which does feed back on heat fluxes. The assumed stationary of the circulation is a limitation of this method, and the AMOC in particular is likely to undergo large $O(1)$ changes over the twentyfirst century. Regarding the second assumption, our Lagrangian model does allow for subduction and reemergence of anomalies, but does not account for dissipation of those anomalies in the interior. Because of the large scale coherence of the forcing pattern in space and time, we expect the interior dissipation of anomalies to be less important than for smaller scale anomalies, such as those forced by interannual climate variability (e.g., Dickson et al. 1988). But given that some of the anomalies will mix with adjacent subsurface layers which do not reemerge, the results can be considered an upper bound on the importance of remote influences.

\section{Results}

a. Exchange time scales between tropical, subtropical, and subpolar regions

An important measure of the intergyre circulation is the time taken for a typical subtropical parcel to reach the SPG. Figure 2 shows an experiment where particles are 
A

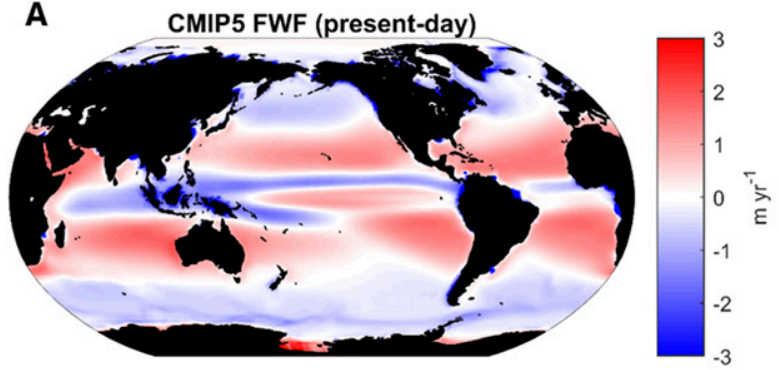

C

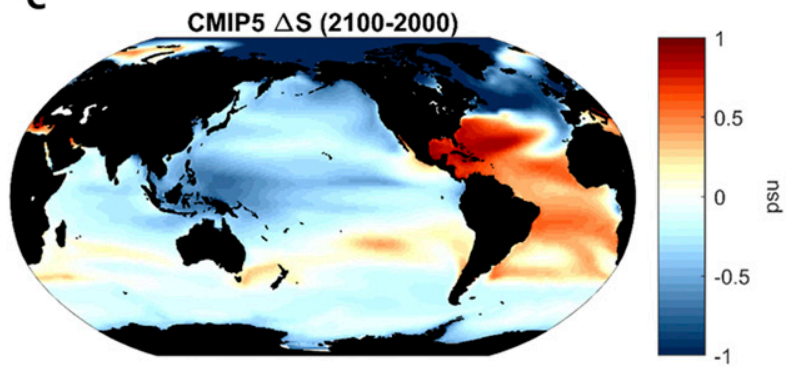

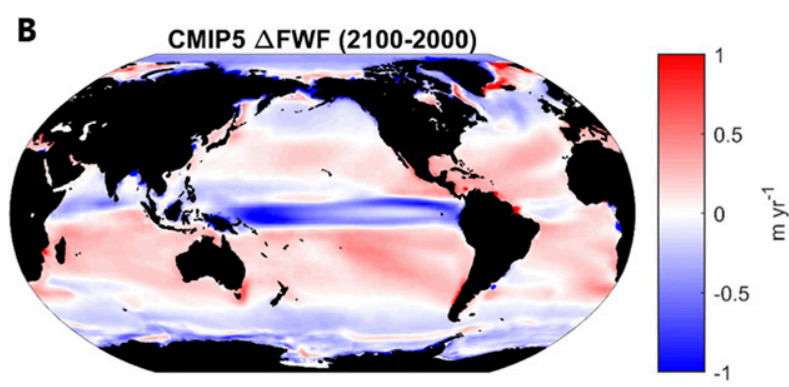

D

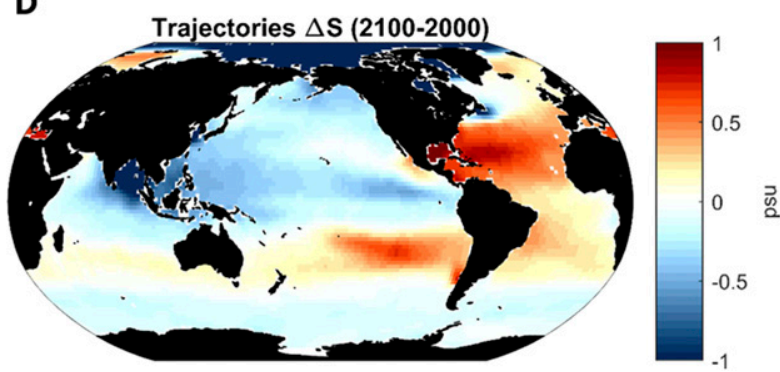

FIG. 3. (a) Present-day FWF ( $\mathrm{m} \mathrm{yr}^{-1}$, positive defined as out of the ocean) for the years 1990-2000 based on an ensemble mean of 28 CMIP5 historical runs, (b) 100-yr change (from 2100 to 2000) in FWF for the RCP8.5 scenario, (c) 100-yr change in surface salinity (psu) from the RCP8.5 scenario of the same 28 CMIP5 models, and (d) accumulated salinity changes along present-day circulation pathways, by applying $\triangle \mathrm{FWF}$ from CMIP5 to $1.5 \times 10^{6}$ reverse trajectories produced from SODA. The passive tracer technique closely matches the coupled models everywhere except in the Atlantic subpolar gyre, as explained in the text.

launched evenly at the surface across the latitudes of the Intertropical Convergence Zone (ITCZ, $\left.5^{\circ} \mathrm{S}-10^{\circ} \mathrm{N}\right)$ and the northern STG $\left(10^{\circ} \mathrm{N}\right.$ to the intergyre boundary) in both the Atlantic and the Pacific. The center panels indicate the cumulative transit time for northern STG particles to reach the SPG, and the right panels shows the time for ITCZ particles to reach either northern or southern STGs.

We calculate the time $\tau_{50}$ at which a majority (50\%) of particles have cumulatively transited from the origin to the destination region. The transit times show that ITCZ waters spread rapidly into the subtropics, with $\tau_{50}<1$ year for all experiments in both Atlantic and Pacific. This time scale is insensitive to eddy representations, as the circulation is dominated by the Ekman-driven subtropical cell.

The subtropical to subpolar exchange is much slower. In the Pacific, $\tau_{50}>100$ years for all experiments. The exchange is negligible without eddy stirring, because there is nearly no mean meridional circulation across the intergyre boundary in the Pacific. For the Atlantic, using the noneddying climatology version SODA, where particles only cross the gyre boundary via steady circulations, $\tau_{50}=83$ years. For the ECCO model without any eddy representations, the result is similar with $\tau_{50}=74$ years. Including the ECCO GM velocities reduces the time scale only slightly to $\tau_{50}=71$ years. In the eddying SODA model, $\tau_{50}=20$ years, which indicates that eddy stirring may greatly increase intergyre exchange.
To test this, we apply an additional stochastic velocity term $\mathbf{u}_{s}$ to particles advected in ECCO. This velocity approximates the effects of the Redi scheme in the Lagrangian frame (van Sebille et al. 2018). We calculate the exchange time scale for trajectories with both the GM velocities and a weak diffusivity $\left(\kappa_{\text {Redi }}=500 \mathrm{~m}^{2} \mathrm{~s}^{-1}\right)$ or a strong diffusivity $\left(\kappa_{\text {Redi }}=2500 \mathrm{~m}^{2} \mathrm{~s}^{-1}\right)$, which gives $\tau_{50}=44$ years and $\tau_{50}=22$ years, respectively. With a large enough diffusivity, the simple random walk model can approximate the intergyre spreading effect of resolved mesoscale eddies.

These results indicate that the speed of intergyre exchange is highly dependent on the isopycnal stirring effect of eddies and only weakly affected by the residual mean circulation represented by GM. The Eulerian mean circulation of the AMOC sets a baseline exchange time scale of $O(100)$ years for STG waters to reach the SPG. The isopycnal diffusion of eddies, which allows waters to cross divergent streamlines of the large-scale circulation at the intergyre boundary, can reduce this exchange time scale to $O(20)$ years.

\section{b. Pathway history and freshwater accumulation}

Figure 3 summarizes the freshwater flux and salinity changes in CMIP5, and the results of accumulating the CMIP5 freshwater flux anomalies along 100 years of reverse trajectories launched globally in SODA. The summed salinity change is calculated along each trajectory 


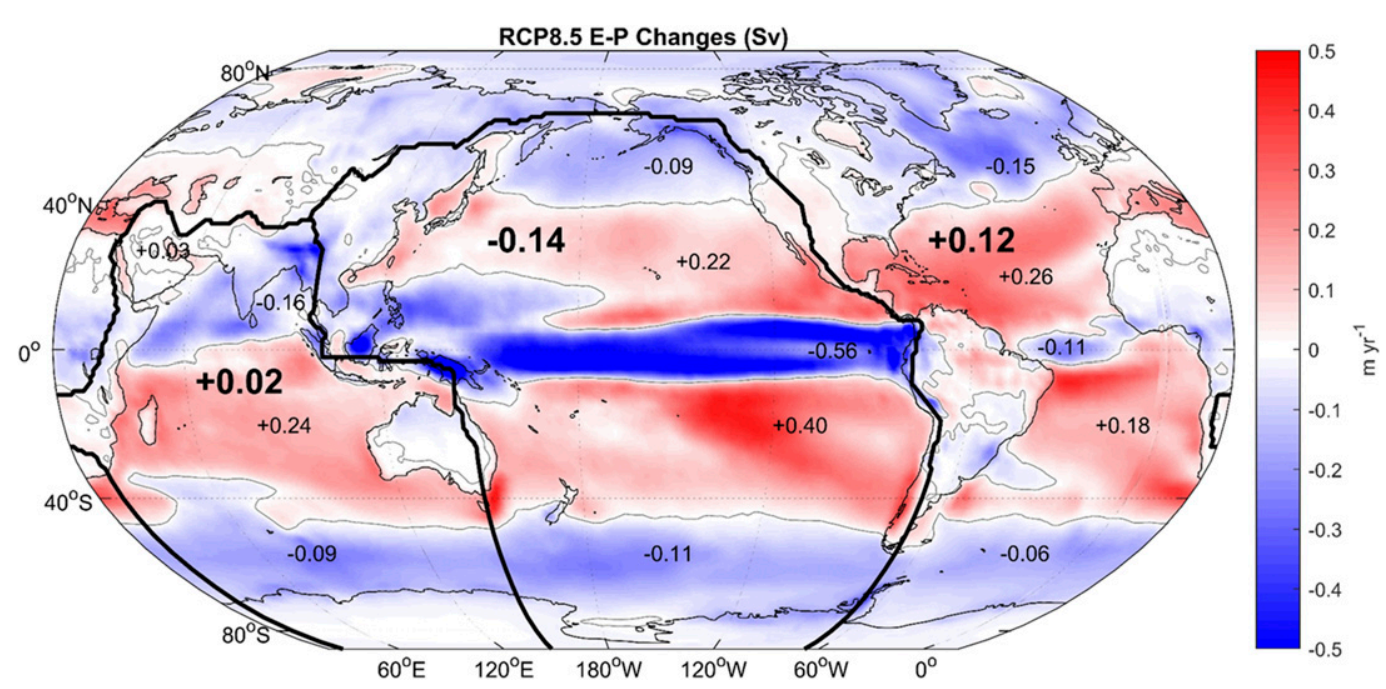

FIG. 4. The 100-yr multimodel mean RCP8.5 change in evaporation minus precipitation $(E-P)$ using the 29 models listed in Table 1, plotted in color $\left(\mathrm{m} \mathrm{yr}^{-1}\right)$. Integrated values are also given in Sverdrups $\left(1 \mathrm{~Sv} \equiv 10^{6} \mathrm{~m}^{3} \mathrm{~s}^{-1}\right)$ for changes in each of the three ocean basins (large font) as delineated by drainage divides (thick black lines). Further values are provided (small font) for subregions as delineated by the zero contours of change (thin black lines).

of an ensemble of $1.0 \times 10^{6}$ particles released evenly across the ocean surface, and then averaged by launch location into $2^{\circ}$ bins.

The results show a striking similarity to the surface salinity changes in CMIP5. As in the coupled models, large freshwater input across the Pacific ITCZ is well distributed into the northern and southern Pacific STGs, balancing the impact of local evaporation. Similarly, in the Atlantic ITCZ region the weaker increase in freshwater input there is overwhelmed by connectivity with the STGs which become much more evaporative, and the Atlantic ITCZ region becomes saltier. In the experiment shown here, which uses the eddying SODA velocities, the Atlantic SPG shows much weaker freshening or increased salinities relative to CMIP5.

\section{c. Competing forcings in the North Atlantic}

In the following sections, we focus on the accumulation of salinity anomalies in the North Atlantic for several reasons. One is that the North Atlantic is a region of large-magnitude salinity changes in CMIP5, with approximately 1-psu freshening for the SPG and 1-psu salinification for the STG in the multimodel mean of RCP8.5. This makes for strongly contrasting signals across the intergyre boundary, whereas in the Pacific the contrast is much weaker because a large increase in ITCZ freshwater input dilutes the salinification signal in the subtropics. Despite the large magnitude of the changes, there is poor agreement between models on the sign of the change in the SPG, particularly on the eastern side of the gyre (see Fig. 7). The other motivation is the role of mean salinity in the high density of subpolar surface waters, which is thought to be an important reason why deep overturning occurs in the North Atlantic but not the North Pacific (Ferreira et al. 2018).

Across CMIP5 models, greenhouse gas forcing causes an amplification of atmospheric moisture transports from the Atlantic to the Pacific (Richter and Xie 2010; Levang and Schmitt 2015), with an additional $0.33 \pm 0.08 \mathrm{~Sv}$ $\left(1 \mathrm{~Sv} \equiv 10^{6} \mathrm{~m}^{3} \mathrm{~s}^{-1}\right)$ exported across the subtropical and tropical latitudes (Levang and Schmitt 2015). In the subpolar and Arctic regions, the Atlantic drainage basin sees an additional $0.15 \pm 0.03 \mathrm{~Sv}$ import of freshwater via the atmosphere (Fig. 4). The net freshwater loss from the Atlantic (north of the Southern Ocean) is $0.18 \pm 0.08 \mathrm{~Sv}$.

This atmospheric response sets up a competition between local freshwater input to the SPG and broadscale freshwater loss from the Atlantic basin as a whole. The influence of the latter depends on the propagation time scale of subtropical waters to the SPG. In the Atlantic, the mean northward upper-level flow of the AMOC works to drive a steady transport from the STG to the SPG. The intergyre boundary is also a region with high mesoscale energy due to the meandering North Atlantic Current (Zhurbas et al. 2014). Hence, transient eddy flows also drive significant exchange across this interface (Bower 1991), as seen in Fig. 2.

Although CMIP5 models do not contain active ice sheet dynamics, several studies have used outputs from CMIP5 in downscaled regional ice models, and estimated 

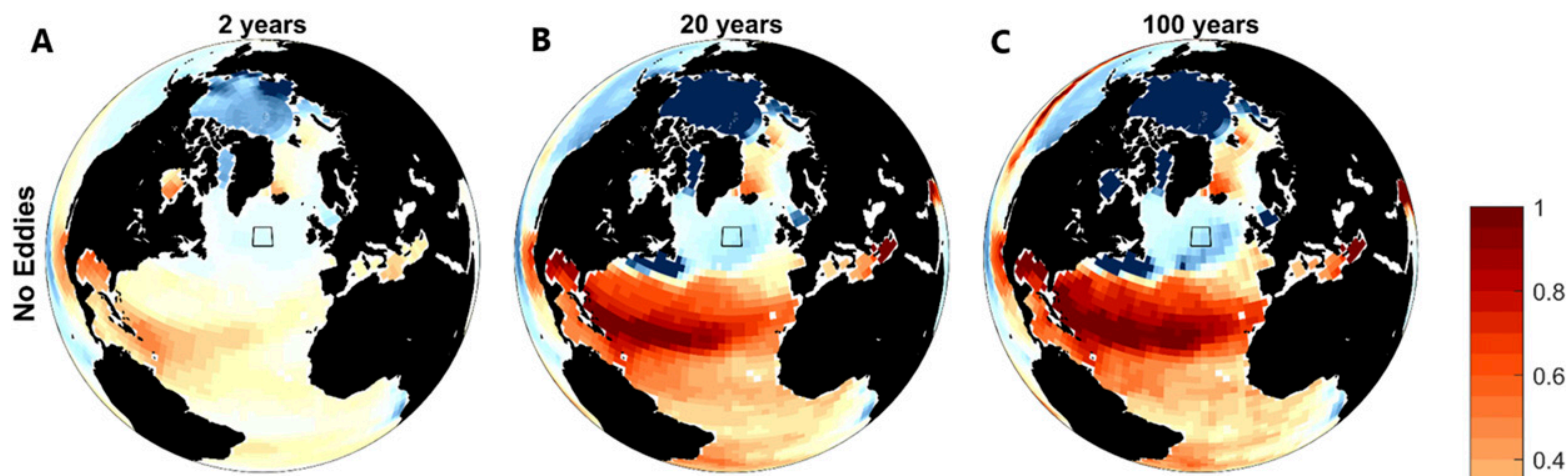

D
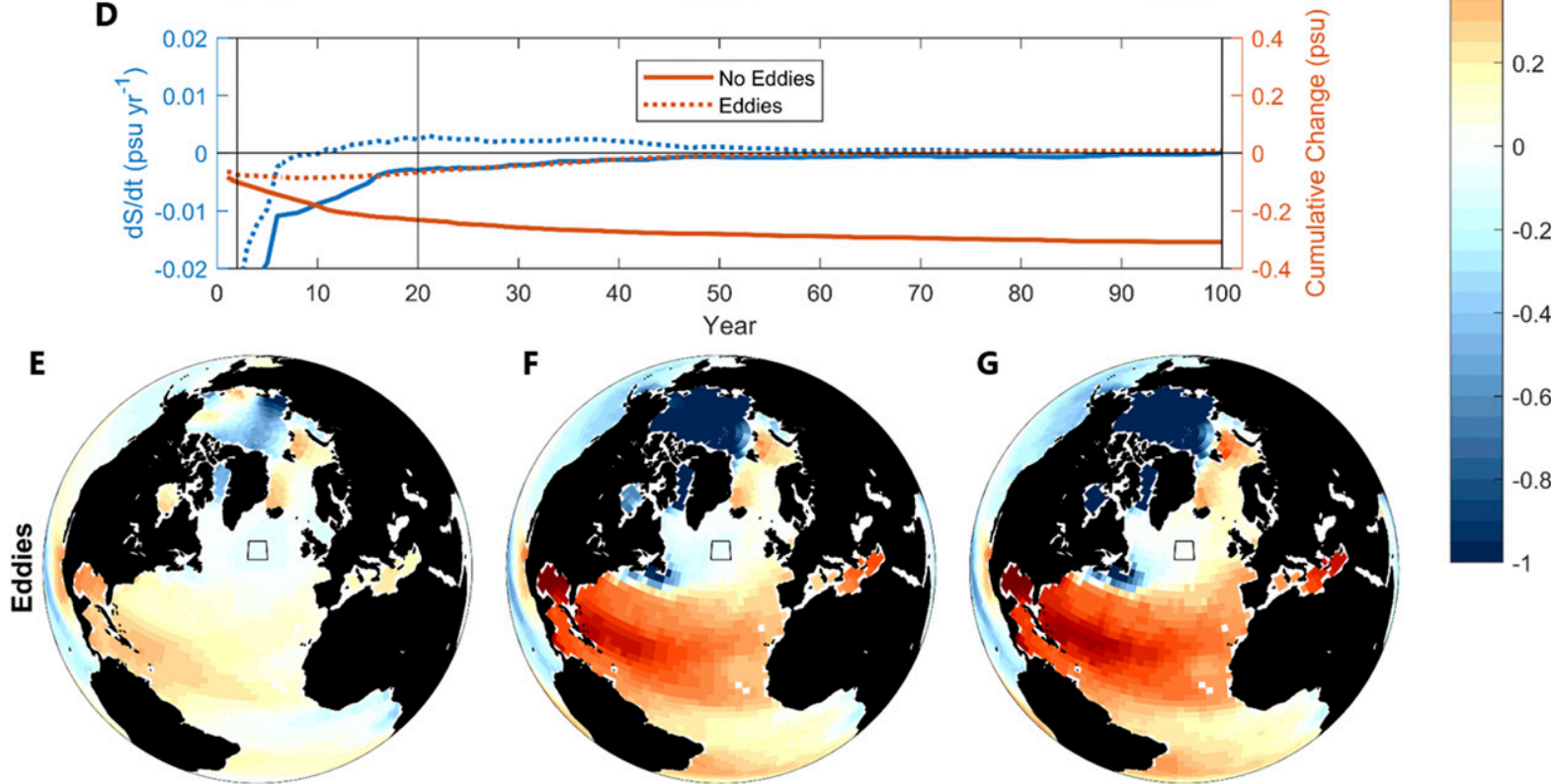

FIG. 5. Maps of salinity change in the North Atlantic, produced by integrating the CMIP5 $\Delta$ FWF forcing backward along trajectories from the year 2100. Maps are calculated for forcing absorbed over (a),(e) the final 2 years (2098-2100) of the trajectories, (b),(f) 20 years (2080-2100), or (c),(g) for 100 years (2000-2100). The maps in (a)-(c) use the SODA climatology without eddies, and the maps in (e)-(g) use the eddying SODA model. (d) Detailed plot of the salinity forcing absorbed by parcels traced back from a subpolar region near $55^{\circ} \mathrm{N}$, $40^{\circ} \mathrm{W}$ (black box), including the cumulative integral of the forcing (red lines) and the instantaneous rate of change at each year (blue lines). Vertical black lines denote the times at which the maps in (a)-(c) and (e)-(g) were produced. For recent history of surface parcels (2 years) local freshening dominates in the subpolar gyre, but when eddy stirring is included, subpolar parcels begin to be influenced by subtropical salinification within a decade. For 2000-2100, the salinity change in the SPG is 0.3 psu saltier with eddies than without.

Greenland meltwater fluxes to be $0.01-0.05$ Sv for the end of the twenty-first century (Vizcaíno et al. 2014; Lenaerts et al. 2015; Yoshimori and Abe-Ouchi 2012). Hence, the expected freshwater forcing from atmospheric fluxes and river runoff exceeds that from glacial melt by at least a factor of 3, although meltwater fluxes may be better localized to freshen deep convection sites. Since glacial melt is not resolved in the CMIP5 experiment, we do not include it here.

\section{d. Salt transport in the subpolar North Atlantic}

Figure 5 shows the reverse trajectory accumulation experiment in the North Atlantic carried out for both the eddying SODA model and the SODA climatology with eddies removed. The accumulation of freshwater anomalies is plotted at different time steps moving backward from the year 2100 to show the role of remote influences over time. The trajectory technique captures the response of the STG and Arctic well when compared to CMIP5, but underestimates the freshening of the SPG, even without eddies. This is in part due to the lack of coupling with circulation changes, as a weaker AMOC reduces the northward flux of salt into the SPG in the coupled models under warming. The trajectories may also underestimate the spreading of runoff input from coastlines, as it is difficult to precisely locate river sources when interpolating the FWF fields from CMIP5 onto other model grids. 

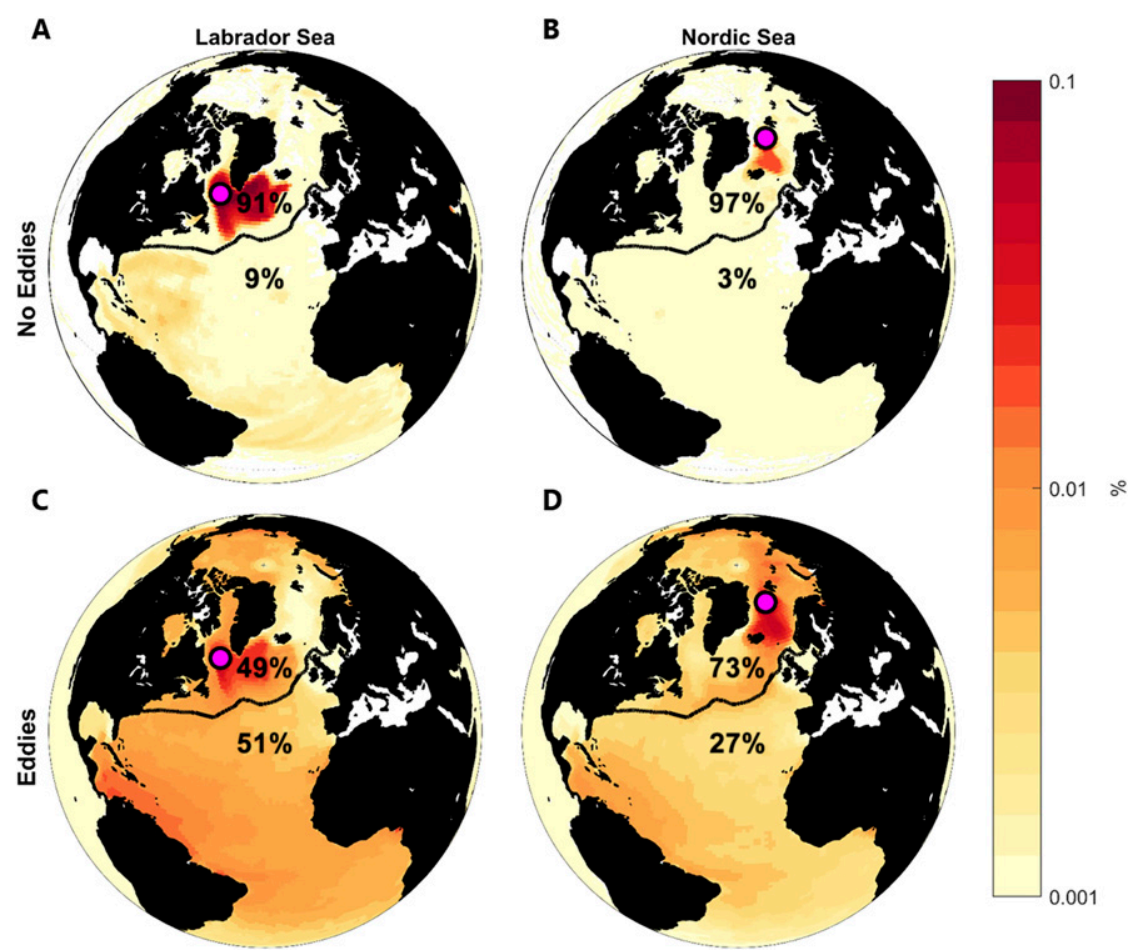

FIG. 6. Maps of the 100-yr surface history $\alpha_{100}$ (see section 2) from $6 \times 10^{4}$ reverse trajectories for two launches sites in the North Atlantic. The locations (pink markers) were chosen in the (a),(c) Labrador Sea, and the (b),(d) Nordic Sea as local maxima of wintertime mixed layer depth, where the majority of deep convection and DWF occurs in SODA. Results are shown for the (top) SODA climatology and (bottom) eddying SODA model. The black line represents a continuous mean dynamic topography contour that divides the subtropical and subpolar gyres. The summed total influence from north (south) of this line is printed above (below) it. Eddies increase the relative influence of the subtropical Atlantic for the DWF sites.

For recent history of surface parcels (2 years) local freshening dominates the SPG, except for a small region of higher salinities in the Nordic Seas which are due to retreating sea ice margins and decreased sea ice melt. When the trajectories are traced backward over decadal and longer time scales, the integrated forcing of the eddying and noneddying models diverges for the SPG (see Fig. 5D). With eddy stirring included, many of the parcels traced backward from the SPG have crossed the intergyre boundary from the STG and accumulated the higher evaporation there. This effect results in 0.3-psu higher salinities in the SPG by the year 2100 between the runs with and without eddies. The majority of the forcing is absorbed over the last 50 years, both because the forcing is treated as a linear trend which goes to zero at the year 2000, and because particles are less likely to be found in the SML as they are traced back in time.

We also use reverse trajectories to investigate in detail the pathway history of surface waters in the deep water formation (DWF) sites. Figure 6 shows the geographic influence of surface forcing on particles launched in the Labrador Sea and the Nordic Seas using the metric $\alpha_{l, t}$ described in Eq. (1), traced backward for 100 years. These locations were chosen as the maxima of March SML depth in SODA, where the strongest deep convection occurs. 60000 particles were launched in $1^{\circ}$ boxes centered on $53^{\circ} \mathrm{W}, 58^{\circ} \mathrm{N}$ and $1^{\circ} \mathrm{W}, 75^{\circ} \mathrm{N}$, the locations of maximum winter SML depth in the SODA model. The metric $\alpha_{l, t}(x, y)$ is calculated in $1^{\circ}$ bins by summing together all trajectories for each launch location and normalizing.

It is clear from Fig. 6 that eddies greatly enhance the connectivity between the deep convection sites and the subtropical Atlantic. In the eddying flow $51 \%$ of particle surface history occurs south of the SPG for the Labrador Sea waters, while this is only $9 \%$ in the noneddying flow. The maps show that the Labrador Sea is generally better connected to the subtropical Atlantic than the Nordic Sea, which is fed more at the surface by Arctic waters.

\section{e. The role of isopycnal mixing in the CMIP5 salinity response}

Particle tracking experiments show that strong isopycnal mixing, either in the form of resolved eddies or a 

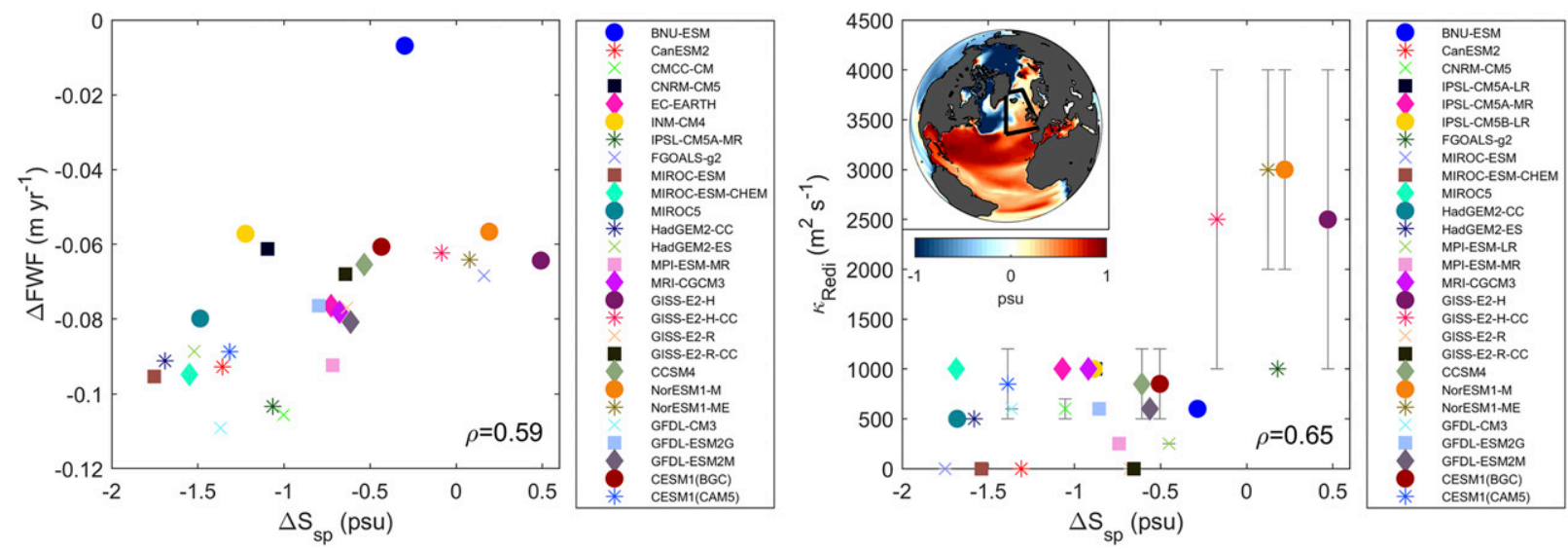

FIG. 7. Scatterplots showing the RCP8.5 eastern subpolar surface salinity change $\left(\Delta S_{\mathrm{sp}}\right)$ plotted against (left) the changes in subpolar freshwater flux $(\Delta \mathrm{FWF})$ and (right) the isopycnal mixing strength $\left(\kappa_{\text {Redi }}\right)$ for 27 CMIP5 models. The $\kappa_{\text {Redi }}$ value was estimated as available from model papers cited in Flato et al. (2014) and given as a range for spatially varying mixing schemes. Eastern subpolar freshening is correlated with both increased freshwater input to the SPG $(\rho=0.59)$ and with lower model diffusivity $(\rho=0.65)$, but with significant scatter in both relationships. Not all models are plotted for both relationships due to data availability. The inset map shows the region over which the salinity and FWF changes were calculated (black box), and the salinity change field in one model (NorESM1-M) is plotted to illustrate the typical spatial pattern seen in the models that show subpolar salinification.

large Redi mixing term, works to carry salty subtropical water into the SPG in the climate warming response. In CMIP5, $17 \%$ of models analyzed here $(5 / 28)$ show a region of increased salinity within the SPG, particularly on the eastern side of the basin where subtropical water follows the North Atlantic Current.

While local freshwater forcing is also expected to play a role, we hypothesize based on the results of prior sections that the strength of isopycnal mixing in CMIP5 models likely impacts their salinity response. To investigate this, Fig. 7 shows the surface salinity change averaged over an eastern subpolar box plotted against both the change in subpolar freshwater forcing and the individual models' isopycnal mixing coefficients. Mixing coefficients were extracted from the manuscripts describing individual model configurations as referenced in Flato et al. (2014). Mixing schemes with spatially varying coefficients are shown as a range, and where geographic maps were provided, the values are estimated by eye for the region of the North Atlantic intergyre boundary.

Both freshwater forcing and mixing are relatively well correlated with surface salinity change but with significant scatter. All models show increased freshwater input (negative $\triangle F W F$ in the left panel of Fig. 7) but with varying salinity responses. Of the five models with the least freshening in this region, four of them have large $\kappa_{\text {Redi }}$ in the range of $1000-4000 \mathrm{~m}^{2} \mathrm{~s}^{-1}$. All other models have $\kappa_{\text {Redi }}<1200 \mathrm{~m}^{2} \mathrm{~s}^{-1}$ and display more significant freshening in the eastern subpolar region.

The comparison is challenging, as model resolution, numerical integration schemes, and other issues also affect total isopycnal diffusion. There are of course many other factors influencing SPG salinity, such as the mean AMOC transport and details of the atmospheric water cycle response. However, stronger diffusion is significantly correlated with less SPG freshening $(\rho=0.65)$, and the general relationship agrees with particle tracking results presented above, where a mixing coefficient of $\kappa_{\text {Redi }} \approx 2500 \mathrm{~m}^{2} \mathrm{~s}^{-1}$ may be necessary to carry a significant amount of anomalously salty subtropical water into the SPG.

\section{Implications for deep convection in the North Atlantic}

The salinity response in the Atlantic SPG is of particular interest because of its effect on surface density in the DWF regions of the AMOC. Past literature suggests that deep convection in the SPG may be influenced by freshwater input to the DWF regions (e.g., Stouffer et al. 2006), which increases the buoyancy of surface waters and inhibits vertical mixing.

Under the classical water cycle intensification pattern imposed by climate warming, the SPG sees increased net precipitation while the STG sees increased net evaporation. In this scenario, we propose that eddy-driven salt transport can act to mitigate the buoyancy increase of SPG waters due to haline effects. By accelerating the intergyre transport of anomalously salty subtropical waters into the SPG, this lessens the effect of local freshwater input. Given the range of mixing parameterizations used in CMIP5 ocean models, this mechanism 


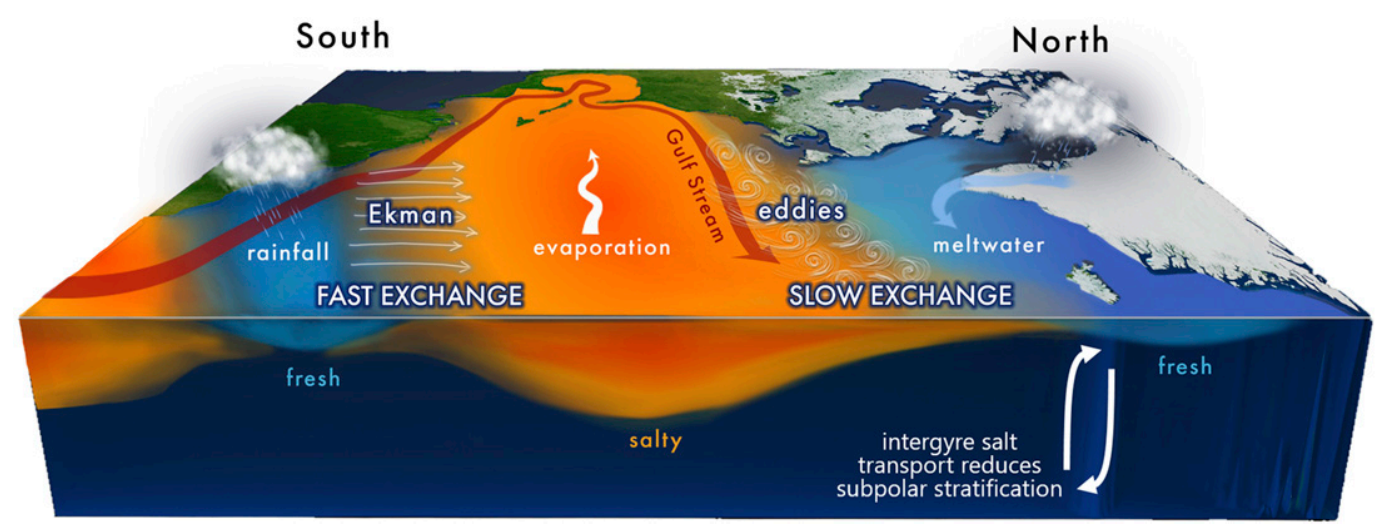

FIG. 8. Amplification of the global water cycle under atmospheric warming increases net evaporation in the subtropics and increases net precipitation in the tropics and high latitudes (where meltwater input also increases). Locally, these fluxes induce a regular pattern of surface salinity anomalies which then propagate along ocean circulation pathways. The tropics communicate rapidly with the subtropical gyre via the shallow Ekman driven cells, while exchange between the subtropical and subpolar gyres is weaker. In a high-resolution model, this transport is predominantly eddy-driven, with a majority of subtropical parcels transiting to the subpolar gyre on decadal time scales. This counters the impact of local freshening, potentially reducing the weakening of deep convection.

likely produces some of the uncertainty between model salinity responses.

\section{Conclusions}

Our results demonstrate that the advective transport time scale between different regimes of the global water cycle is key to understanding the climate salinity response. When the time scale of forcing change is slow relative to the exchange time scale, ocean circulation is able to mix together different regional forcing. Across the tropics and subtropics, the circulation is indeed very fast relative to present-day climate change, and the local salinity anomalies forced by water cycle intensification become mixed across these regions.

Between the subtropical and subpolar regions, the exchange time scale is much slower and largely driven by eddy stirring (Fig. 8), especially in the Pacific where no mean overturning circulation connects the gyres. In the Atlantic, we find that an eddying circulation transports a majority of subtropical surface waters to the SPG within 20 years, which may be considered fast relative to centennial climate change. In a noneddying flow, this time scale is a factor of 4 larger, which is slow relative to climate change. Therefore, we expect less mixing of the subtropical and subpolar salinity signals when eddy stirring is weak. Although the data are noisy due to other influences, we find some support in the CMIP5 experiment that models with stronger isopycnal mixing show less freshening in the Atlantic SPG due to this mechanism.

In the weak isopycnal mixing case where the intergyre exchange time scale is $O(100)$ years, nonlinear advection feedbacks of the AMOC may activate well before any significant amount of salty subtropical water penetrates the SPG. In the strong mixing case, the intergyre salt exchange may counteract freshening in the SPG and help to support DWF.

We reiterate that the trajectory accumulation method used here has limitations, as it ignores advection feedbacks, interior mixing, and other nuances of the coupled simulations. Hence, salinity response maps shown in this study should not be taken as accurate projections for the coupled climate system. Rather, we use the technique to demonstrate that

- treating salt as a passive tracer captures the first-order dynamics of the 100-yr coupled response for most regions;

- intergyre exchange carries anomalously salty water northward into the SPG under water cycle intensification;

- this exchange is greatly enhanced by the isopycnal diffusion of mesoscale eddies, which has widely varying strength in the coarse CMIP5 models; and

- evaporation in the North Atlantic STG has the potential to balance out a significant portion ( 0.3 psu in the experiments here) of local freshening in the SPG and AMOC deep convection sites under present-day warming scenarios.

These results also have implications for numerical ocean model development. Different eddy mixing rates at the intergyre boundary can produce divergent climate responses in oceanic tracer fields when the forcing signal differs between the gyres, as it does for salinity. Here, the along-isopycnal Redi term is shown to be particularly important in the North Atlantic. Many CMIP5-generation models use a simple constant 
Redi mixing rate between 500 and $1000 \mathrm{~m}^{2} \mathrm{~s}^{-1}$. Observationally based estimates show that while these values may be appropriate for more quiescent regions such as the subtropical gyre centers, isopycnal mixing rates at the energetic intergyre boundary may be several orders of magnitude higher (Zhurbas et al. 2014; Abernathey and Marshall 2013). Capturing this spatial variability of mixing in model parameterizations is evidently important to the ocean's climate response.

Acknowledgments. We acknowledge the World Climate Research Programme's Working Group on Coupled Modelling, which is responsible for CMIP, and we thank the climate modeling groups (listed in Table 1 of this paper) for producing and making available their model output. We also thank the creators of the SODA and ECCO reanalysis products. This work was supported by NASA Headquarters under the NASA Earth and Space Science Fellowship Program Award 80NSSC17K0372, and by National Science Foundation Award OCE-1433132. The SODA outputs used here can be accessed at http://www.atmos.umd.edu/ ocean/, and the ECCO outputs at https://ecco.jpl.nasa.gov/. Data from the CMIP5 ensemble is available at https:// esgf-node.llnl.gov/projects/esgf-llnl/. The particle tracking code used for these experiments can be found at https:// github.com/slevang/particle-tracking.

\section{REFERENCES}

Abernathey, R. P., and J. Marshall, 2013: Global surface eddy diffusivities derived from satellite altimetry. J. Geophys. Res. Oceans, 118, 901-916, https://doi.org/10.1002/jgrc.20066.

Bower, A. S., 1991: A simple kinematic mechanism for mixing fluid parcels across a meandering jet. J. Phys. Oceanogr., 21, 173-180, https://doi.org/10.1175/1520-0485(1991)021<0173: ASKMFM $>2.0 . \mathrm{CO} ; 2$.

Brambilla, E., and L. D. Talley, 2006: Surface drifter exchange between the North Atlantic subtropical and subpolar gyres. J. Geophys. Res., 111, C07026, https://doi.org/10.1029/ 2005JC003146.

Buckley, M. W., and J. Marshall, 2016: Observations, inferences, and mechanisms of the Atlantic Meridional Overturning Circulation: A review. Rev. Geophys., 54, 5-63, https://doi.org/ 10.1002/2015RG000493.

Burkholder, K. C., and M. S. Lozier, 2011: Subtropical to subpolar pathways in the North Atlantic: Deductions from Lagrangian trajectories. J. Geophys. Res., 116, C07017, https://doi.org/ 10.1029/2010JC006697.

Caesar, L., S. Rahmstorf, A. Robinson, G. Feulner, and V. Saba, 2018: Observed fingerprint of a weakening Atlantic Ocean overturning circulation. Nature, 556, 191-196, https://doi.org/ 10.1038/s41586-018-0006-5.

Carton, J. A., G. A. Chepurin, and L. Chen, 2018: SODA3: A new ocean climate reanalysis. J. Climate, 31, 6967-6983, https:// doi.org/10.1175/JCLI-D-18-0149.1.

Delworth, T. L., and Coauthors, 2012: Simulated climate and climate change in the GFDL CM2.5 high-resolution coupled climate model. J. Climate, 25, 2755-2781, https://doi.org/ 10.1175/JCLI-D-11-00316.1.

Dickson, R. R., J. Meincke, S.-A. Malmberg, and A. J. Lee, 1988: The "great salinity anomaly" in the Northern North Atlantic 1968-1982. Prog. Oceanogr., 20, 103-151, https://doi.org/ 10.1016/0079-6611(88)90049-3.

Durack, P. J., S. E. Wijffels, and R. J. Matear, 2012: Ocean salinities reveal strong global water cycle intensification during 1950 to 2000. Science, 336, 455-458, https://doi.org/10.1126/ science. 1212222 .

Ferreira, D., and Coauthors, 2018: Atlantic-Pacific asymmetry in deep water formation. Ann. Rev. Earth Planet. Sci., 46, 327-352, https://doi.org/10.1146/annurev-earth-082517-010045.

Flato, G. M., J. Marotzke, B. Abiodun, P. Braconnot, S. Chou, W. Collins, and P. Cox, 2014: Evaluation of climate models. Climate Change 2013: The Physical Science Basis, T. F. Stocker et al., Eds., Cambridge University Press, 741-866.

Forget, G., J.-M. Campin, P. Heimbach, C. N. Hill, R. M. Ponte, and C. Wunsch, 2015: ECCO version 4: An integrated framework for non-linear inverse modeling and global ocean state estimation. Geosci. Model Dev., 8, 3071-3104, https:// doi.org/10.5194/gmd-8-3071-2015.

Foukal, N. P., and M. S. Lozier, 2016: No inter-gyre pathway for sea-surface temperature anomalies in the North Atlantic. Nat. Commun., 7, 11333, https://doi.org/10.1038/ncomms11333.

Fox-Kemper, B., and Coauthors, 2011: Parameterization of mixed layer eddies. III: Implementation and impact in global ocean climate simulations. Ocean Modell., 39, 61-78, https://doi.org/ 10.1016/j.ocemod.2010.09.002.

Gaspar, P., Y. Grégoris, and J.-M. Lefevre, 1990: A simple eddy kinetic energy model for simulations of the oceanic vertical mixing: Tests at station Papa and long-term upper ocean study site. J. Geophys. Res., 95, 16 179-16-193, https://doi.org/10.1029/ JC095iC09p16179.

Gebbie, G., and P. Huybers, 2019: The Little Ice Age and 20th-century deep Pacific cooling. Science, 363, 70-74, https:// doi.org/10.1126/science.aar8413.

Gent, P. R., and J. C. Mcwilliams, 1990: Isopycnal mixing in ocean circulation models. J. Phys. Oceanogr., 20, 150-155, https:// doi.org/10.1175/1520-0485(1990)020<0150:IMIOCM > 2.0.CO;2.

Held, I. M., and B. J. Soden, 2006: Robust responses of the hydrological cycle to global warming. J. Climate, 19, 5686-5699, https://doi.org/10.1175/JCLI3990.1.

Kuhlbrodt, T., A. Griesel, M. Montoya, A. Levermann, M. Hofmann, and S. Rahmstorf, 2007: On the driving processes of the Atlantic meridional overturning circulation. Rev. Geophys., 45, RG2001, https://doi.org/10.1029/2004RG000166.

Lange, M., and E. van Sebille, 2017: Parcels v0.9: Prototyping a Lagrangian ocean analysis framework for the petascale age. Geosci. Model Dev., 10, 4175-4186, https://doi.org/10.5194/ gmd-10-4175-2017.

Large, W. G., J. C. McWilliams, and S. C. Doney, 1994: Oceanic vertical mixing: A review and a model with a nonlocal boundary layer parameterization. Rev. Geophys., 32, 363-403, https://doi.org/10.1029/94RG01872.

Lavender, K. L., R. E. Davis, and W. B. Owens, 2002: Observations of open-ocean deep convection in the Labrador Sea from subsurface floats. J. Phys. Oceanogr., 32, 511-526, https://doi.org/ 10.1175/1520-0485(2002)032<0511:OOOODC>2.0.CO;2.

Lenaerts, J. T. M., D. L. Bars, L. Kampenhout, M. Vizcaino, E. M. Enderlin, and M. R. Broeke, 2015: Representing Greenland ice sheet freshwater fluxes in climate models. Geophys. Res. Lett., 42, 6373-6381, https://doi.org/10.1002/2015GL064738. 
Levang, S. J., and R. W. Schmitt, 2015: Centennial changes of the global water cycle in CMIP5 models. J. Climate, 28, 6489-6502, https://doi.org/10.1175/JCLI-D-15-0143.1.

- and _ 2020: What causes the AMOC to weaken in CMIP5? J. Climate, 33, 1535-1545, https://doi.org/10.1175/ JCLI-D-19-0547.1.

Marshall, J., J. R. Scott, K. C. Armour, J.-M. Campin, M. Kelley, and A. Romanou, 2015: The ocean's role in the transient response of climate to abrupt greenhouse gas forcing. Climate Dyn., 44, 2287-2299, https://doi.org/10.1007/s00382-014-2308-0.

Qin, X., E. van Sebille, and A. Sen Gupta, 2014: Quantification of errors induced by temporal resolution on Lagrangian particles in an eddy-resolving model. Ocean Modell., 76, 20-30, https://doi.org/10.1016/j.ocemod.2014.02.002.

Redi, M. H., 1982: Oceanic isopycnal mixing by coordinate rotation. J. Phys. Oceanogr., 12, 1154-1158, https://doi.org/ 10.1175/1520-0485(1982)012<1154:OIMBCR > 2.0.CO;2.

Richter, I., and S. P. Xie, 2010: Moisture transport from the Atlantic to the Pacific basin and its response to North Atlantic cooling and global warming. Climate Dyn., 35, 551-566, https:// doi.org/10.1007/s00382-009-0708-3.

Stouffer, R. J., and Coauthors, 2006: Investigating the causes of the response of the thermohaline circulation to past and future climate changes. J. Climate, 19, 1365-1387, https://doi.org/ 10.1175/JCLI3689.1. van Sebille, E., and Coauthors, 2018: Lagrangian ocean analysis: Fundamentals and practices. Ocean Modell., 121, 49-75, https:// doi.org/10.1016/j.ocemod.2017.11.008.

Vizcaíno, M., W. H. Lipscomb, W. J. Sacks, and M. van den Broeke, 2014: Greenland surface mass balance as simulated by the Community Earth System Model. Part II: Twenty-firstcentury changes. J. Climate, 27, 215-226, https://doi.org/10.1175/ JCLI-D-12-00588.1.

Weijer, W., and Coauthors, 2019: Stability of the Atlantic meridional overturning circulation: A review and synthesis. J. Geophys. Res. Oceans, 124, 5336-5375, https://doi.org/ 10.1029/2019JC015083.

Yoshimori, M., and A. Abe-Ouchi, 2012: Sources of spread in multimodel projections of the Greenland Ice Sheet surface mass balance. J. Climate, 25, 1157-1175, https://doi.org/ 10.1175/2011JCLI4011.1.

Zhurbas, V., D. Lyzhkov, and N. Kuzmina, 2014: Drifter-derived estimates of lateral eddy diffusivity in the World Ocean with emphasis on the Indian Ocean and problems of parameterisation. Deep-Sea Res. I, 83, 1-11, https://doi.org/10.1016/ j.dsr.2013.09.001.

Zou, S., and M. S. Lozier, 2016: Breaking the linkage between Labrador Sea Water production and its advective export to the subtropical gyre. J. Phys. Oceanogr., 46, 2169-2182, https:// doi.org/10.1175/JPO-D-15-0210.1. 